\title{
CAN CONSENSUS STANDARDS BRING WIDER ACCEPTANCE OF FIBRE-OPTIC SENSORS IN SOIL-STRUCTURE INTERACTION MONITORING?
}

\author{
J. K. Jeyapalan ${ }^{* 1}$ and W. R. Habel ${ }^{2}$ \\ ${ }^{1}$ Civic Enterprises, LLC, New Milford, USA \\ ${ }^{2}$ Engineering Consultant for Structural Health Monitoring, \\ formerly Federal Institute for Materials Research and Testing (BAM,) Germany \\ *orresponding author
}

\begin{abstract}
Many of the older SDO (Standard Development Organizations) have stood the test of time, bringing recognition and credibility to those industries that work within their procedures. These standards reduce the time it takes engineers to write bidding documents and technical specifications. The standards bring an added degree of comfort for the engineers, contractors and users, who know that the thorough vetting process built as part of the consensus building is based on the balanced representation of consumers, users, producers and those of general interest. Standards help to form contracts between buyers and sellers. Standards form the backbone of establishing the "standard of care" in our judicial system. In a way, the buyers and sellers have the standards provide a preview of what case law is likely and help avoid errors and omissions. The biggest benefit of global standards is that these documents pave the way to new technologies to become widely accepted in the market place. This paper describes the need for well-developed and consistent standards in the FOS (Fibre Optic Sensor) industry, then outlines the current status of the FOS industry's coordination with well-established SDOs, and makes the case for continuing to bring the Fibre Optic Sensor industry under the purview of well-established SDOs, in order to calm the fears of those doubting the usefulness of FOS. In addition to the continued reliance on established SDOs, a case is made for a truly independent, self-governing standard writing platform composed of FOS industry sellers, buyers and subject matter experts.
\end{abstract}

\section{Introduction}

Fibre optic sensors offer a great potential in numerous industrial and engineering projects. They are preferred even more if special conditions require the avoidance of the application of conventional electrical sensors. The scientific background for optical fibre sensors is well developed; however, not all users are convinced that fibre optic sensors provide long-term stable function in harsh environmental conditions. There are still some hinderences with respect to long-term reliable use. First, some sensors available on the market are sometimes not appropriately characterized and described. Second, application procedures are not always well validated due to a lack of understanding of the mechanical, physical or chemical issues in the interface zone between the sensor and the object that is being monitored.

Users therefore need standardized description of the sensor system performance, recommendations as to what aspects must be considered for reliable application and operation of sensors, and finally how to handle the application of sensors under possibly harsh environmental conditions. Technical rules must be provided. A few guidelines for the appropriate specification and use of fibre optic sensors have been published. Several European and international activities have been launched to encourage the development of additional standards for special applications. The quality of a measurement system is represented by the reliable use of system components. Mostly, the weakest point is the sensor itself, and its use under real measurement conditions. Examples are:

- Thermal stress on sensing element during application

- Sensor reaction to mechanical or thermal impacts during operation

- Sensor behavior/aging under maintained vibration

- Sensor behavior (including cabling) under wet conditions

- Creep of applied sensor depending on temperature and strain

- Drift of the sensor signal due to temperature and other factors.

- Durability of materials under thermal, chemical, mechanical conditions.

When users are going to pursue a measurement task, they need a comprehensive overview on the basic characteristics of the sensor system components, their performance, and basic rules on how to use the measurement system practically. This use generally includes the selection of appropriate system components, the selection of appropriate and long-term reliable installation components such as fixing elements, adhesives, and covering materials. Finally, established application procedures must be used to eliminate weaknesses and avoid failure of installed sensor components. When using rather new sensor technologies such as fibre sensor technology, some additional aspects must be considered. One aspect 
concerns the terminology used in this field. Physicists do speak another language compared to engineers, practitioners or system designers. Therefore, the terms used by everyone in the FOS industry must be agreed upon. Another aspect concerns the performance description of the system components. The lack of standardized testing methods to prove the performance of fibre-optic sensors often causes problems. For example, there was a long way to come to develop consistent standards for resistance strain gauges and corresponding devices. Today, many standards, guidelines and certified application procedures, including training programs to get a certificate, are available to enable users to collect reliable measurement results from applied resistive strain sensors.

In the same way, the established use of fibre-optic sensor systems on-site requires standards and guidelines. No underground railway company, for example, will integrate fibre-optic measurement systems in their tunnels without having standards that describe and define important parameters and procedures. At the very least, hand-outs or companyrelated guidelines, which are not yet standards, yet which generally summarize the essential data for design, application and operation of fibre-optic sensor systems must be available. Users need precise information about the component's characteristics, reproducibility, long-term stability, expected drifts and creep, parameter limits, and eventually, information about the expected uncertainty of the results measured. The design work for a sensor system and the choice of an appropriate application procedure must follow specific demands according to the measurement task. In the past few years, several activities have come into play to make available more standards and guidelines for fibre-optic sensors. The sections below summarises these activities.

\section{Pioneering efforts in standards and guides}

Development of standards and guidelines for fibre-optic sensor's performance specification, and relevant testing procedures have been discussed in the scientific community as well as in the industry since the mid-nineties of the last century. There are many standards for description, evaluation and use of fibre-optic components in data communication and telecommunication. Guidelines or standards for fibre-optic sensors were still an exception. The first standard draft on generic specification of fibre-optic sensors - IEC (International Electrotechnical Commission) 61757 - was published in 1995; the first Working Draft P952/D24 for a specific type of a fibre sensor - the fibre-optic gyroscope was published in December 1996. The IEC standard 61757, part 1: 'Generic standard' has been revised in 2010 and 2011, and was in the Final Draft International Standard, which contained the text intended for publication for final approval, in early 2012. Publication of this standard was in April 2012. The most important prerequisite when a new measurement technology is to be launched is the availability of a consistent" standardized" terminology. Not only do different users make use of non-consistent terms and descriptions for the fibre-optic sensor technology, but even all the fibre sensor experts do not carry the same meaning on what specific terms associated with characterization, validation and application of sensing systems convey. It is worthwhile to notice that standards for fibre-optic sensors must also cover: characteristic details related to the respective physical sensor mechanism, the sensor response to differences measured, application, and finally specific perturbing influences coming from environmental stimulants. These sensor-specific issues mark other aspects in fibre-optic sensor technology and need to be in the scope of standardization step-by-step.

The wide range of applications for FOS technology can be seen from the following example application. Different types of fibre-optic sensors based on glass or polymeric fibres are used to evaluate material behavior or to monitor the integrity and long-term stability of load-bearing structure components. Fibre-optic sensors have been established as a new and innovative measurement technology in very different fields, such as material science, civil engineering, light-weight structures, geotechnical areas as well as chemical and highvoltage substations. Very often, mechanical quantities such as deformation, strain or vibration are requested. Measurement of chemical quantities in materials and structure components, such as $\mathrm{pH}$ value in steel reinforced concrete members, however, also provides information about the integrity of concrete structures.

A special fibre-optic chemical sensor for monitoring the alkaline state ( $\mathrm{pH}$ value) of the cementitious matrix in steelreinforced concrete structures with the purpose of early detection of corrosion-initiating factors is desired. The subject of the use of several fibre-optic sensor technologies in geotechnical engineering. One example concerns the use of high-resolution fibre Fabry-Perot sensors that can be embedded in concrete. Applying usual dynamic low-strain or high-strain testing methods, such highly dynamic sensors embedded along the concrete piles allow the assessment of the integrity and the bearing behavior of large concrete piles in existing foundations or during and after its installation.

Another example concerns FBG (fibre Bragg grating) sensors attached to anchor steels (micro piles) to measure the strain distribution in loaded soil anchors. POF (Polymer optical fibres) can be - because of their high elasticity and high ultimate strain - well integrated into textiles to monitor their deformation behavior. Such "intelligent" textiles are capable of monitoring displacement of soil or slopes, critical mechanical deformation in geotechnical structures (dikes, dams, and embankments) as well as in masonry structures during and after earthquakes.

To understand a soil-structure interaction system's overall behavior, or to enhance the operating efficiency of aged structures, sensors are applied to components or even embedded into its material. Such sensors must work appropriately to provide safe information about the soilstructure's behavior under load conditions as well as in case of sudden damage or deteriorating processes. The first requirement needed to get appropriately working sensor systems is to use sensors validated according to standards. Another challenge is to install them without losing their calibration or their overall performance. The most significant 
challenge for sensor experts is to reduce application-related influences. Guidelines should therefore define validation procedures for sensors and recommend methods to test and evaluate the behavior of applied sensors. Description of the performance of sensors comprises many aspects: sensor characteristics (sensitivity), functional parameters (measurement accuracy, stability), interface definitions and interchangeability, environmental protection, characteristic features of the interrogation system used, measures enabling cost reduction, application and service and maintenance aspects.

In the past decade, many small and medium companies have provided sensor components or complete fibre-optic measurement systems for strain, temperature or other quantities. Despite the clear advantages of fibre-optic sensors for many measurement tasks, missing standards on how to characterize, specify, design and use fibre-optic sensor systems have made the dissemination and/or the use of excellent technical solutions difficult. The lack of a clear performance specification makes the comparison of products provided by different manufacturers difficult. Not only is characterization and specification of a fibre-optic sensor system important, but also its correct selection and application.

Standards should also provide users, consultants, and technical staff on-site a survey of all technical aspects that are intrinsically tied to application and installation of sensing components. Especially in selected fields with specific challenges, e.g. geotechnical areas, structural engineering, or offshore environments, it is necessary to translate generic statements of IEC or ISO (International Standards Organization) standards into specific requirements.

Companies, user communities or international societies usually do this. For example, members of the ISHMII (International Society for Structural Health Monitoring of Intelligent Infrastructure) - a non-profit organization of leading structural health monitoring institutions, deal with development of standards for establishing new sensor and monitoring technologies. They do this translation work in their specific fields of use.

All of the above are major milestones demonstrating the enormous value efforts of standardization brought toward wider use of FOS.

\section{Standardization of FOS in the IEC}

\subsection{Completed projects; newly established IEC standards}

A few FOS standard projects have already been completed. The first bilingual guideline focused on FBG-based strain sensors was the German VDI/VDE (Verein Deutscher Ingenieure/Verband Deutscher Elektrotechniker) 2660 Guideline: 'Experimental Stress Analysis - Optical Strain Sensor based on fibre Bragg grating; Basics, Characteristics and its Testing' published in July 2010. The international generic FOS standard was published in 2012: the IEC standard on "Fibre Optic Sensors" originally numbered as 61757-1. This standard encouraged the development of a fibre-optic standard family (see Figures 1 and 2). In order to have a logical structure in numbering FOS IEC-Standards, numbering code as shown in Table 1 was defined. According to this numbering code, the generic standard is now numbered as IEC 61757.

In the meantime, another two components of this IEC standard family are completed. Based on the German VDI/VDE 2660 Guideline, the IEC 61757-1-1 standard on "Strain measurement - Strain sensors based on fibre Bragg gratings" was developed in the IEC Subcommittee 86C, Working Group 2 and published in February 2016. In the same way, the IEC 61757-2-2 standard on "Temperature measurement Distributed sensing" based on the SEAFOM (International Joint Industry Forum aimed at promoting the growth of fibre optic monitoring system installations in the upstream oil and gas industry) document SEAFOM-MSP-01 "Measurement

Specification for DTS (Distributed Temperature Sensing)" originally published in March 2010 by the SEAFOM Measurement Specification Working Group was also completed and published in May 2016. Figures 1 and 2 show the structure of the IEC FOS standard family; Figure 1 shows the specification detailed for strain measurements, Figure 2 shows the same one detailed for temperature measurements. An extended description of the content of these standards can be found in Habel et al. (2007, 2009, 2011, 2012, 2013, 2014, 2015), Habel and Krebber (2011), and Habel, Krebber and Daum (2015).

\subsection{New projects}

In October 2015, Subcommittee 86C decided to start the development of a standard document for the use of temperature sensors based on fibre Bragg gratings. This work has been proceeding within the German VDI Committee 2.17 from December 2015; the first draft for discussion in the IEC SC86C was presented at the IEC WG 2 meeting immediately before the EWOFS in Limerick on May 30-31, 2016; it was following approved to develop a Committee Draft. It was again intended to go the same way as in the past: to collaborate with the development of a corresponding VDI guideline. In December 2018, the green paper of the VDI Guideline 2660, part 2:

"Technical temperature measurement - Optical temperature sensor based on fibre Bragg gratings - Recommendation on temperature measurement and statement of measurement uncertainty" was published and commented by end of February 2019. Based on this VDI Guideline 2660, part 2, the draft of IEC 61757-2-1: "Fibre Optic Sensors-Temperature measurement Temperature sensors based on fibre Bragg gratings" will be completed and published for expert discussion in the second part of 2019 . 
Figure 1 Structure of IEC fibre-optic sensor standards related to strain measurement

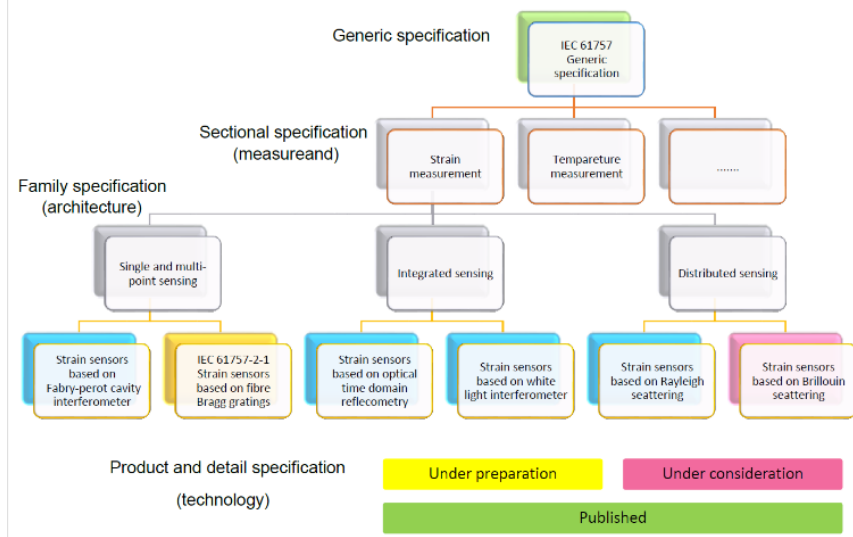

Figure 2. Fibre-optic sensors standards related to temperature measurements

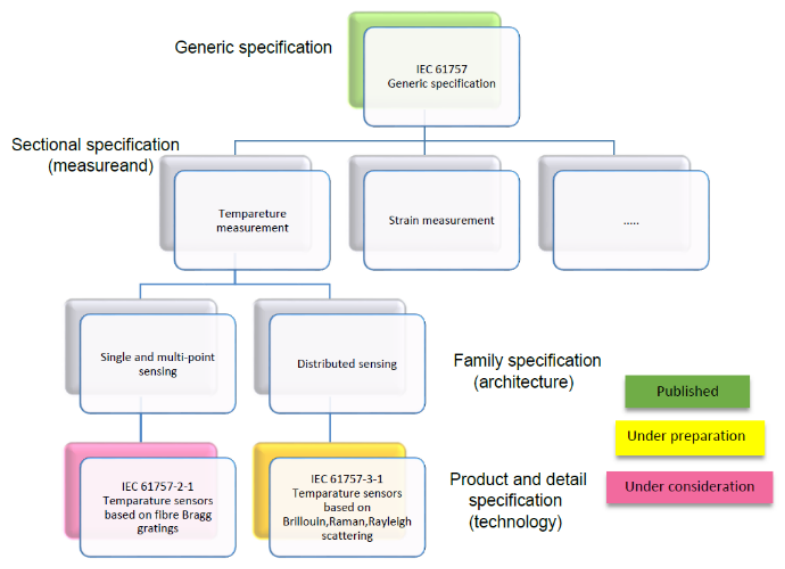

\subsection{Projects planned}

Because of wide use of distributed fibre-optic strain sensors based on stimulated Brillouin backscattering, and with respect to the increasing use of distributed fibre-optic acoustic sensor solutions, two new projects have been proposed in the IEC subcommittee 86C: IEC 61757-1-2: Fibre Optic Sensors - Part 1-2: Strain measurement - Distributed sensing, and 61757-3-2: Fibre Optic Sensors - Part 3-2: Distributed acoustic sensing.

Table 1. Numbering code for IEC standards on Fibre Optic Sensors

\begin{tabular}{|c|c|c|c|c|c|}
\hline Measurand (M) & $\begin{array}{c}\mathrm{FBG} \\
(-\ldots-1)\end{array}$ & $\begin{array}{c}\text { Distributed } \\
\left(-\ldots \_2\right)\end{array}$ & $\begin{array}{l}\text { Polarization } \\
\text { change } \\
(-\ldots-3)\end{array}$ & Fabry-Perot & $\ldots$ \\
\hline Strain $(-1-\ldots)$ & $-1-1(\mathrm{a})$ & $-1-2(b)$ & & & \\
\hline Temperature $(-2 \ldots)$ & $-2-1$ (b) & $-2-2(a)$ & & & \\
\hline Acoustic signals $(-3-\ldots)$ & & $-3-2(b)$ & & & \\
\hline Electric Current (-4-...) & & & $-4-3(b)$ & & \\
\hline Pressure & & & \multirow{3}{*}{\multicolumn{2}{|c|}{$\begin{array}{l}\text { (a) Published } \\
\text { (b) Under preparation }\end{array}$}} & \\
\hline Chemical (PH) & & & & & \\
\hline & & & & & \\
\hline
\end{tabular}

\section{FOS standardization in the ASTM}

Whereas the IEC standards cover rather basic aspects for preparation, testing, validation and description of sensors and sensor systems, more application-related standards or guidelines are needed to handle different fibre-optic sensor systems on-site. The Global Optical Fibre Sensing System (OFSS) Task group of the ASTM Technical Committee F36 "Technology and Underground Utilities", especially Subcommittee F36.10 "Optical Fibre Systems within Existing Infrastructure" focused its work - as a standardization body on such practical aspects.

When the first author served as a consultant to Washington DC Clean Rivers Project tunnels, the amplitude of the ground movements measured was in fractions of an inch while the noise in the traditional instrumentation systems used was even higher, Jeyapalan et al. (2014, 2015). Therefore, the predictions made per Attewell et al. (1986) did not have a way to be compared with field observations. This led the team to consider OFSS methods, but ultimately, they were not implemented. The lack of consensus standards for OFSS methods was a contributory consideration in the client's decision. This market need was the primary driver for the birth of the ASTM F36 Global OFSS Task group (Iten et al. 2015). The two companion standards brought to the global market by F36 were ASTM F3079 (2014) and ASTM F3092 (2014).

Some of the significant publications which demonstrated the advantages of using OFSS in civil infrastructure include Vorster et al (2005) on assessing the impact of ground movements due to construction activities nearby on buried pipelines, Briançon et al. (2004) and Nancey et al. (2007) on a composite fibre-optic sensor-enabled geotextile for soil strain assessment using the Fibre Bragg Grating technology, Calderon and Glisic (2012) and Glisic (2011) on field observations using OFSS and the accuracy of embedded longgauge optical fibre strain sensors, Glisic and Inaudi (2008) on the use of OFSS for structural health monitoring, Klar et al (2008) on analysis and field monitoring, Mohamad et al. (2014) on temperature and strain sensing using Brillouin Optical Time Domain Reflectometry (BOTDR), Mohamad ( 2012) and Mohamad et al. (2012) on tunnel induced response of old brick tunnels and new tunnels.

Artières et al. (2010) showed also the use of OFSS to monitor hydraulic structures. Iten (2011) and Iten et al. (2011) demonstrated the effective use of optical fibre sensing systems to a wide range of geotechnical applications. Given that the DOFSS (distributed optical fibre sensing systems) are the type that are most widely used on soil-structure interaction monitoring projects, to provide a basic working knowledge on DOFSS to the geotechnical engineers reading this paper, more details on this form of FOS are discussed in the next few sections with the reasonable success achieved in writing pertinent standards for the Brillouin scattering based strain and temperature measurement. 


\section{Rayleigh, Raman and Brillouin Systems}

There are three types of distributed fibre optic sensors based on interactions of the launched light (laser) beam with the constituent atoms and molecules of the fibre material. Due to inhomogeneities in the material; these interactions generate light scattering in the optical fibre and part of the light is reflected back (backscattering). Depending on the type of interaction, different backscattering mechanisms can be initiated and used for distributed sensing.

Distributed sensing always focusses on extended measurement areas. If distances longer than 600 metres have to be bridged, glass fibres are used. They enable sensor gauge lengths of hundreds of metres or even tens of kilometres. If geotechnical areas of limited extensions have to be monitored, polymer optical fibres are more efficient because they allow to measure strain increase by up to $20 \%$ or even $30 \%$. Such fibres are usually used to monitor mining areas or sliding slopes, see for example Liehr, Lenke, Krywult et al. (2009).

The three distributed sensor effects are based on Rayleigh scattering, Raman scattering and Brillouin scattering. If the light sent back was elastically scattered and no energy was transferred to the glass, this sensor effect is called Rayleigh backscattering. Changes in the attenuation profile along the fibre show possible changes in the length of the fibre, which means strain at those points where the attenuation changes occur. Using the time-domain based backscattering (OTDR) or the frequency-domain based backscattering method (OFDR), the location of strain changes can be identified. Rayleigh backscattering sensors are preferably used to measure strain.

If the temperature distribution along fibre sensor cables is to be measured or observed, the Raman backscattering sensor effect should be used. Raman scattering is based on an increased vibration of the molecules in the optical material due to a temperature increase in that material. The light wave interaction with the matter leads to an (inelastic) energy exchange, which is associated with an intensity shift of the back-reflected light depending on the corresponding temperature change. The temperature dependence of Raman sensor is used in distributed fibre-optic temperature sensor systems, for example to detect leakage water engineering structures and high pressure gas pipelines, hot spots in coal mining areas or deformations on gas and oil pipelines.

Inelastic scattering can also be stimulated by mechanical excitation of the matter, e.g. by a strong laser pulse. A strong laser pulse launched into the end of one fibre called pump beam induces acoustic vibrations (so called phonons) in the material. Such sound waves can be considered as periodic, mechanical density fluctuations in the fibre. These acoustic waves meet the scattered low-intensity optical wave (photons). This physical effect is called stimulated Brillouin Scattering and a frequency shift in the backscattered signal is recorded. If there is any mechanical (or thermal) change in the fibre material, e.g. caused by compression, tension, shear or any deformation changes, the Brillouin frequency will change and can be recorded. Brillouin sensors are preferably used to measure strain over fibre lengths of up to $60 \mathrm{~km}$ and more; temperature measurements are also possible over such distances; however the backscattered temperature signal is weaker than a strain signal.

The specification of the measurement systems defines all metrological details. Depending on the performance of the signal recording capabilities in the device, the resolution of the measurement value (strain, temperature) strongly varies; strain resolution of up to $10 \mu \mathrm{m} / \mathrm{m}$ and temperature resolution of up to $0.5 \mathrm{~K}$ can be achieved. The spatial resolution to identify the location of the event to be measured depends on the length of the sensor fibre; spatial resolution of a few $\mathrm{cm}$ can be achieved. More details about these distributed sensor effect can be found in a previous paper of Habel and Jeyapalan (2019).

\section{SHM standardization in the ISHMII}

ISHMII as a non-profit organization of leading (mostly civil) structural health monitoring (SHM) institutions and individuals focusses also on development of standards to adjust international SHM activities. SHM activities are not only related to development and use of sensors and whole measurement systems but substantially on the development of SHM strategies, optimization of damage detection technologies and improvement of methodologies to achieve sophisticated concepts for risk assessment and management by online monitoring of all interactions of the structure components during their life cycle.

An important objective of SHM guidelines and codes is to provide all necessary (sensor) information about the behavior of the structure to estimate the remaining life and to develop optimal maintenance strategies and scheduling based on a critical lifecycle cost-benefit-analysis. Documents which combine and harmonize existing approaches for integrated management systems with those of new sensor standards are currently developed. There was established a task force "Standardization" under the leadership of Zhishen Wu (Ibaraki University, Japan), co-chaired by Yi-Qing Ni (The Hong Kong Polytechnic University, Kowloon - Hong Kong). The first survey and ISHMII state-of-the-art report on SHM (Structural Health Monitoring) standardization activities from different counties and regions was presented in a Special Session on Standardization at the SHMII-7 Conference in Turin/Italy in July 2015.

The ISHMII code series consists of three parts (levels):

- Level 1: General principles, definitions and approaches,

1. Introduction, describing the scope of the model code, basic concepts, category of structures/structure crowds, objectives of SHM, relations among the visual inspection, NDE inspection and SHM methodologies

2. Definitions for Damage, Performance, Health, and SHM

3. Composition of SHM and Monitoring Strategies

4. Sensors/sensing System, a) Sensors Technologies, b) Imple-mentation Methods, c) Performance Requirement and Evaluations

5. Data Acquisition and Management Systems 
6. Networking, Communication, and Control

7. Measurement Calibration and Data Interpretation

8. Structural Diagnosis and Prognosis; algorithms on detection/identification/calculation of structural condition parameters and damages, assessment on Environmental Conditions and Loads, performance Evaluations; evaluations of Residual Life

9. Design Examples

10. References

11.Appendix: Commercially Available Sensor Technologies. - Level 2 addresses different major structures and major sensing technologies, such as design guidelines for different structures, and a guideline for fibre-optic sensors based SHM for Civil Infrastructures.

- Level 3 will consider different countries or regions. The fibreoptic sensor part is an important part of this set of standards, because this sensor technology has huge advantages in civil, geotechnical and structural engineering.

Co-operating countries are Austria, Canada, China (Mainland, Hong Kong), Germany, Japan, South Korea and USA. The ISHMII Task Force members have close and cooperative relations with the committees of IEC, SAE and others. More about ISHMII activities can be found in Habel and Wenzel (2015).

\section{Best practices guides from the University of Cambridge Center for smart infrastructure and construction (CSIC)}

CSIC has published a series of best practices guides and one of these cover the subject of DOFSS (CSIC, 2016). Given the clout of the University of Cambridge around the globe and the high productivity of the CSIC, it is reasonable to conclude that additional guides are likely to be available from CSIC in the coming years.

\section{Future for the OFSS global task group}

The following projects were started in 2015 and work has been on hold until a suitable platform is found to complete and publish the following work items into global standards:

1)Standard practice for the Installation of optical fibre cables along pipelines for leak detection using distributed vibration, strain, and thermal sensing: Lead Author Dr. Greg Duckworth (Raytheon BBN, US)

Scope: The purpose of this guidance note is to address the means and methods for the use of distributed optical fibre sensors for detection and localisation of leaks in buried terrestrial pipelines that transport or contain oil, gas, chemicals, water, slurries, and sewage. Selection of suitable materials, design, installation, data collection, data processing, and reporting of results will be detailed. It is the responsibility of each operator to adopt these recommendations according to their needs and to the specific site conditions of installation and environment.
Objective: To prepare and disseminate an authoritative document that contains good practices on how to design and install an optical fibre distributed acoustic, strain, or thermal monitoring system for reliable detection and localization of leaks along terrestrial pipelines.

The need for and anticipated benefits: Pipelines leaking products such as oil, gas, chemicals, water, slurries, and sewage particularly in highly populated urban areas cause damage to the environment and human health with significant potential for catastrophic and costly pipeline failure. Optical fibre distributed sensors have the capability to monitor changes in the strain, optical path, index of refraction, and temperature along a cable. This data can be translated into precise detection of leaks spatially and temporally, offering tools for better management of such pipelines to allow for rapid leak detection and intervention. Despite the wide spread use of terrestrial pipelines to transport fluids of such types for thousands of kilometres around the world in just about every country, no standards on good practices exist. There is a dire need for this standard and anticipated benefits to the public of the proposed standard are improvement in safety and protection of human health.

2)Standard practice for the Use of optical fibre distributed temperature sensing to detect leaks in above-ground ammonia, ethylene and LNG pipelines - Lead author: Dr Daniele Inaudi (Smartec, Switzerland)

Scope: The purpose of this guidance document is to describe the optical fibre leak detection system on ammonia, ethylene or LNG above-ground (Liquefied Natural Gas) pipelines, to detail its efficiency, and to propose good installation, usage and maintenance practices for these systems. It is the responsibility of each operator to adopt these recommendations according to their needs and to the specific site conditions of installation and environment.

Objective: To prepare and disseminate an authoritative document that contains good practices on how to detect and localize as fast and precisely as possible any liquid ammonia leak, using distributed optical fibre temperature sensors that can be advantageously deployed on ammonia pipelines. The functionality of this optical fibre sensing system is based on a physical principle called "Raman scattering," and on the possibility of measuring the temperature of each metre of the sensing cable from the analysis of the optical signal reflected by the fibre.

The need for and anticipated benefits: Pipelines leaking products such as ammonia, ethylene, and LNG particularly in highly populated urban areas cause damage to the environment and human health. Given the capability of optical fibre DTS to monitor minute temperature changes and translate such data into precise detection of leaks spatially and temporally offer tools for better management of such pipelines. Despite the wide spread use of above ground pipelines to transport fluids of such types for thousands of kilometres around the world in just about every country, no standards on good practices exist. There is a dire need for this standard and anticipated benefits to the public of the proposed standard are improvement in safety and protection of human health. 
3)Standard Practice for the Use of optical Fibre Bragg Grating for civil engineering system monitoring; Lead authors: Prof An-Bin Huang (National Chiao Tung University, Taiwan), Dr Ying Huang (North Dakota State University, US), Dr Hui Li (Harbin Institute of Technology, China), Prof Sun Tong (City University, UK)

Scope: This guide addresses the use of optical fibre Bragg grating (FBG) as the sensitive element for strain and/or temperature measurement for the monitored material or as a part of a transducer for other types of physical or chemical quantity measurement, e.g. through careful layout of FBG(s) or effective coating of material on the surface of an FBG. This standard applies to all FBGs made in an optical fibre. This standard refers to the FBG based measurements in a range of frequencies for structural, geotechnical, hydrological, transportation, environmental monitoring and other purposes related to civil engineering systems.

Objective: To provide a guideline that contains important characteristics of FBG based sensors and their readout units (i.e., the interrogators), good practices for field sensor installation and procedures for data interpretation.

The need for and anticipated benefits: Because of the unique capabilities of the FBG sensor, its application in civil engineering system is expanding rapidly. The FBG sensors have been installed in various types of structures such as buildings, power plants, bridges, wind turbines, and tunnels for safety monitoring. The technology has also been used for ensuring slope stability and monitoring ground subsidence using FBG based displacement and pore water pressure transducers. FBG sensors have been developed and deployed for air humidity monitoring and toxic gas detection as well. Despite the wide use of FBG around the world, no standards on good practices exist yet. There is a need for this standard leading to anticipated benefits to the longevity of civil engineering systems and safety of our environment.iber

\section{Scope:}

With the increasing number of industrial applications for distributed fibre-optic strain and temperature sensing technologies, there is a growing demand for comparable performance data of the sensing instruments. A comprehensive set of clear definitions for the resolution and accuracy characteristics - taking the unconventional nature of distributed sensing data into account - shall help industrial and academic users to evaluate the technology and introduce its benefits into new applications.

This Best Practice Guidance Note shall address the need for clear definitions for the performance characteristics of distributed fibre-optic temperature and strain sensing systems (DTSS), especially for the terms of resolution and accuracy of the spatially resolved data. Distributed data is often interpreted as a chain of point-sensors, delivering independent data from defined points along the sensing fibre at fixed spatial intervals, which is often defined as the spatial resolution. In many sensing applications, this interpretation doesn't reflect the true nature of distributed sensing data for the following reasons:

a. The data points of a measurement trace of a truly distributed fibre sensor are not independent from each other; they rather correspond to nodes along a curve that represent the physical (and therefore continuous) strain / temperature distribution. This difference to a chain of spatially fixed-point sensors is important when comparing different sets of data from one sensor to another over time, especially while using automated algorithms for data processing.

b. The term "spatial resolution" does not necessarily correspond to the spacing of the data points. Spatial oversampling allows to increase the density of spatial information, while the classic definition of spatial resolution might not be affected.

The terms "accuracy", "repeatability", "reproducibility", "cross-sensitivity" and "sensor calibration" need to be handled with respect to the substantial differences between distributed sensing technologies and point-wise or quasi-distributed sensing technologies, but also to the variations among different distributed sensing principles (Brillouin DTSS, Raman DTS, Rayleigh OTDR / OBR etc.

4)New Standard practice for the Use of distributed optical fibre sensing systems for strain monitoring of reinforced concrete pile foundations during static load testing Lead authors: Dr Nicholas de Battista (University of Cambridge, UK), Dr Cedric Kechavarzi (University of Cambridge, UK), Dr Hisham Mohamad (Institute of Technology Petronas, Malaysia)

1. Introduction

1.1. Static pile load testing

1.1.1. Purpose

1.1.2. Load testing methods

1.1.3. Typical instrumentation and interpretation of results

1.2. Basic principles of distributed fibre optic strain sensing

1.2.1. Optical fibres and fibre optic cables

1.2.2. Optical scattering and backscatter spectrum

1.2.3. Effect of temperature and strain

1.2.4. Other important system specifications

1.2.5. Brillouin analysers

2. Installation and operation of a distributed fibre optic strain sensing system for pile load tests

2.1. Preparation

2.1.1. System design

2.1.2. Assembly of fibre optic cables

2.1.3. Testing of fibre optic cables

2.2. Installation

2.2.1. Attaching fibre optic cables to pile reinforcement

2.2.2. Pile installation with fibre-optic instrumentation (single cage, multiple cage)

2.2.2.1. Bored piles

2.2.2.2. CFA piles

2.2.3. Site considerations (exiting pile head, routing, monitoring location, testing)

2.3. Measuring concrete temperature and strain during curing

2.4. Measuring pile strain during static load testing

2.5. Health and safety considerations

2.5.1. Considerations when handling of optical fibres 
2.5.2. Considerations when installing fibre optic cables in piles

3. Data analysis and reporting

3.1. Calculating strain and temperature from measurement data

3.2. Relating measurements to pile depth and ground stratigraphy

3.3. Deriving pile and soil engineering parameters

3.4. Installation, monitoring and interpretation reports Appendix A: Glossary of terms

Appendix B: Specification checklist for a distributed fibre optic sensing system for pile monitoring

Appendix C: Sample risk assessments

5)New Practice for Spatial and measurand resolution and accuracy definitions in distributed fibre-optic temperature and strain sensing data Lead Authors: Nils Nöther (fibrisTerre Systems GmbH, Germany), Avi Zadok (BarIlan University, Israel), Xiaoyi Bao (University of Ottawa, Canada), ...

2. Scope:

With the increasing number of industrial applications for distributed fibre-optic strain and temperature sensing technologies, there is a growing demand for comparable performance data of the sensing instruments. A comprehensive set of clear definitions for the resolution and accuracy characteristics - taking the unconventional nature of distributed sensing data into account - shall help industrial and academic users to evaluate the technology and introduce its benefits into new applications.

This Best Practice Guidance Note shall address the need for clear definitions for the performance characteristics of distributed fibre-optic temperature and strain sensing systems (DTSS), especially for the terms of resolution and accuracy of the spatially resolved data. Distributed data is often interpreted as a chain of point-sensors, delivering independent data from defined points along the sensing fibre at fixed spatial intervals, which is often defined as the spatial resolution. In many sensing applications, this interpretation doesn't reflect the true nature of distributed sensing data for the following reasons:

a. The data points of a measurement trace of a truly distributed fibre sensor are not independent from each other; they rather correspond to nodes along a curve that represent the physical (and therefore continuous) strain / temperature distribution. This difference to a chain of spatially fixed-point sensors is important when comparing different sets of data from one sensor to another over time, especially while using automated algorithms for data processing.

b. The term "spatial resolution" does not necessarily correspond to the spacing of the data points. Spatial oversampling allows to increase the density of spatial information, while the classic definition of spatial resolution might not be affected.

The terms "accuracy", "repeatability", "reproducibility", "cross-sensitivity" and "sensor calibration" need to be handled with respect to the substantial differences between distributed sensing technologies and point-wise or quasi-distributed sensing technologies, but also to the variations among different distributed sensing principles (Brillouin DTSS, Raman DTS, Rayleigh OTDR / OBR etc.)

3. References documents

4. Terminology

5. Performance parameter definitions

5.1. Spatial resolution

5.2. Spatial accuracy / spatial sampling rate

5.3. Measurand accuracy

5.4. Measurand repeatability

5.5. Measurand reproducibility

5.6. Measurand cross-sensitivity

5.7. Dynamic range / Optical loss budget

5.8. Measurement time

5.9. Handling interdependencies of performance parameter

6. Practical considerations for the quantitative analysis of distributed sensing data

6.1. Calibration and coefficient determination for distributed fibre-optic sensors

6.1.1. Distributed strain sensing fibres

6.1.2. Distributed strain sensing cables

6.1.3. Distributed temperature sensing fibres

6.1.4. Distributed temperature sensing cables

5.2 Separation of strain and temperature in distributed fibreoptic strain and temperature measurements

7. Comparability of distributed sensing data

8. Quality control

9. Key words

Bibliography

6)Best Practice Guidance for the Use of distributed fibre optic temperature sensing for locating illicit connections on sewers - Leading authors: Dr Cedric Kechavarzi and Phil Keenan (University of Cambridge, UK), and Olga Brzezinska (Atkins, UK)

Scope: This guide describes the use of distributed fibre optic sensing for measuring temperature inside separate sewer systems to detect illicit discharges of storm water to foul sewers and of foul sewage to storm sewers. This standard does not deal with the operation of combined sewer systems. This standard will address the installation methods of optical fibre sensing cables into sewers and the data analysis and interpretation processes required to identify potential anomalous connections.

Objective: To introduce an innovative, efficient and costeffective method to detect illicit connections using distributed optical fibre sensing and to disseminate good practices on how to design, install and operate such a system to obtain meaningful outcomes.

The need for and anticipated benefits: Illicit connections, most often unintended, of storm water to foul sewers and of foul sewage to storm sewers, are a major problem associated with separate sewer systems. Storm water infiltration into a foul sewer can lead to the exceedance of the sewer and treatment plant design capacity and potentially local flooding and over spilling of foul sewage. On the other hand, foul sewage flow into storm sewer can result in the release of untreated sewage in surface water and the environment. The efficient removal of 
illicit connections is therefore of a large benefit to the public both in sanitary and economical terms. The removal of these connections, however, requires precise knowledge of their location. In addition, illicit discharges are intermittent. Hence the detection of these connection requires monitoring system with good spatial and temporal resolution that can be deployed over kilometres of sewer networks. Distributed temperature sensing based on Raman scattering provides such a monitoring system. By detecting the sudden changes in temperature of the sewer liquid due to the difference in foul and storm water temperature at any given time and distance along an optical fibre the system can help to accurately pinpoint anomalies in operation. This standard will help disseminate the knowledge and know-how gained by researchers and practitioners and provide guidance to the end user to ensure the correct use of distributed temperature sensing and the reliable assessment of sewer performance.

Impact and value:

- this good practice guide will demonstrate the utility of distributed fibre optic temperature sensing in detecting sewer operation and malfunction;

- data visualization sewer tools introduced in this guide will showcase the operation patterns indicative of certain sewer events (illicit discharge, domestic sewer operational patterns, sewer blockages, manhole overflow events) of value to asset owners and managers;

- this guide will illustrate how a network of fibre optic sensors can provide asset managers with a real-time view of the condition of their critical assets;

- this innovative monitoring technology provides ample data that informs sewer planning departments to ensure asset integrity is maintained and prevents the interruption of service due to failure.

\section{Benefits of global standards}

Well respected standard development organizations (SDO's) offer inclusive forums and the benefits from the development, publication and distribution of their standards around the globe help the optical fibre sensing industry and its users significantly. Given many of these are the oldest standard writing bodies in the world, and have stood the test of time, they bring instant recognition and credibility to the FOS industry. This should calm the fears of those doubting the usefulness of OFSS. These standards reduce the amount of time it takes engineers to write bidding documents and technical specifications. The standards bring an added degree of comfort for the engineers, contractors and the users knowing that the thorough vetting process built as part of the consensus building within these platforms based on the balanced representation of consumers, users, producers and those of general interest. Standards help to form contracts between buyers and sellers. In case of disagreements or disputes, standards form the backbone of establishing the "standard of care" in our judicial system. In a way, the buyers and sellers have the standards provide a preview of what case law is likely to be written and help them become aware of how to avoid errors and omissions. The biggest benefit of global standards is that these consensus documents pave the way to new technologies to become more widely accepted in the market place. Given the above benefits, writing standards is a worthy pursuit for all those who are willing to set aside their own personal interests and wish to give back to mankind more than what they have taken.

\section{Conclusions}

Standardization activities to provide fibre-optic sensors for use in SHM systems have been strongly pushed in the last decade. The generic IEC FOS standard and first basic sensor standards as well as application guidelines are now available. Several groups and committees are increasingly active; however, communication between participants of these groups is very important to avoid parallel activities, uncoordinated terminology use, and concurrent recommendations. Continued close cooperation between experts from IEC, ISHMII, SAE, IEEE, CSIC and the Global OFSS Task Group and other standardization and guideline groups should be encouraged.

\section{Where do we go from here?}

Much work on writing standards and guides remains to be done. No single group can meet the growing demands for standards like those completed but unfilled needs in the other forms of technology and their application. Each group should continue to contribute using their strengths in certain focused areas of FOS. Given the serious problems experienced within ASTM F36 by the Global OFSS Task Group, the most rewarding option could be that the FOS industry forms its own publishing body like, for example, the geotextile industry and the oil and gas industry have done. This business model of writing and publishing their own guidelines through GSI (Geosynthetic Institute) seems to have proved beneficial to all members of that industry to fuel its growth. The fibre optic sensor industry could also follow this model toward prosperity. These are true only to the extent the SDO (Standard Development Organization) operates within Bylaws, Rules and Regulations, and has an independent oversight body. Voting members of technical committees within the SDO must meet requirements of technical training in the subject matter. Member classification must be decided using a rigorous screening process.

To answer "Can consensus standards bring wider acceptance of fibre-optic sensors in soil-structure interaction monitoring? the reader is reminded of the old adage "A rising tide lifts all boats."

\section{References}

Artières, O., Galiana, M., Royet, P., Beck, Y. L., Cunat, P., Courivaud, J. R., Fry, J. J., Faure, Y. H., Guidoux, C. (2010). "Fibre Optics Monitoring Solutions for Canal Dikes". Proc. PIANC MMX Congress, Liverpool, UK. ASTM F3079 (2014) "Standard Practice for Use of DistributedOpti Optical Fibre Sensing Systems for Monitoring the Impact of Ground Movements During Tunnel and Utility 
Construction on Existing Underground Utilities," ASTM International, West Conshohocken, PA.

ASTM F3092 (2014) "Standard Terminology Relating to Optical Fibre Sensing Systems," ASTM International, West Conshohocken, PA.

Attewell, P.B, Yeates, J \& Selby, A.R., (1986) "Soil Movements Induced by Tunneling and Their Effects on Pipelines and Structures", Blackie.

Briançon, L., Nancey, A., Caquel, F. and Villard, P. (2004).

New Technology for Strain Measurements in Soil and the

Survey of Reinforced Earth Constructions. Proc, EUROGEO

3,March 2004, Munich, pp. 471-476.

Calderon, P., and Glisic, B. (2012). "Influence of Mechanical and Geometrical Properties of Embedded Long-gauge Strain Sensors on the Accuracy," Measurement Science and Technology, 23(6), no.065604 (15pp).

CSIC (2016) Distributed Fibre Optic Strain Sensing for Monitoring Civil Infrastructure: A Practical Guide by Cedric Keshavarz, Kenichi Soga, Nicholas de Battista, Loizos Pelecanos, Mohammed Elshafie and Robert J Mair.

Publication date: 29 July 2016

Glisic, B. (2011). "Influence of Gauge Length to Accuracy of Long-gauge Sensors Employed in Monitoring of Prismatic Beams," Measurement Science and Technology, 22 (3), art. no. 035206 (13pp).

Glisic, B. and Inaudi, D.(2008) "Fibre Optic Methods for Structural Health Monitoring, "John Wiley \& Sons, Chichester (ISBN: 978-0-470-06142-8).

Habel, W. R and Krebber, K.(2011), "Fibre-optic sensor application in civil and geotechnical engineering" Photonic Sensors Vol. 1, No. 3: 268-28

Habel, W., R., Krebber, K. and Daum, W., (2015)

"Standardization in Fibre-3optic Sensing for Structural Safety - Activities in the ISHMII and IEC," Proc. SPIE, 9436, 94360S; doi:10.1117/12.2185602.

Habel, W., R. and Wenzel, H., (2015) "Importance of standardization to promote the use of SHM systems." SMAR2015 3rd Conference on Smart Monitoring, Assessment and Rehabilitation of Civil Structures, Antalya/Turkey, September 7-9. Abstract book. CD-ROM, paper ID: 66. Empa Zurich/Switzerland.

Habel, W. R., (2007) "Standards and Guidelines: Could They Enhance User Confidence in Fibre Sensor Technology?

"Proceedings of the SPIE conference July.

Habel, W.R., (2012) Advances in Developing Standards for Fibre-Optic Sensors, "6th European Workshop on Structural Health Monitoring, Dresden, Germany.

Habel, W.R., Schukar, V., and Hofmann, D. (2014)

"Requirements to Establish Fibre-optic Sensors for Monitoring of Structures, "7th European Workshop on Structural Health Monitoring, Nantes, France.

Habel et al, (2009) "Guidelines for the Characterization and Use of Fibre-Optic Sensors-Basic Definitions and a Proposed Standard for FBG-Based Strain Sensors, International conference on Optical fibre sensing, SPIE

Habel, W.R., Schukar, V. G. and Kusche, N. (2013) "Fibre optic strain sensors are making the leap from lab to industrial use - reliability and validation as a precondition for standards IOP Publishing Ltd Measurement Science andTechnology,
Volume 24, Number 9

Habel, W. R. and Jeyapalan, J. K. (2019), "Benefits of standardization of FOS in soil-structure interaction applications", Geotechnical Engineering. Journal of SEAGS-AGSSEA To be published in June.

IEC 61757:2018 "Fibre-optic Sensors - Generic Specification" IEC 61757-1-1 (2016), "Fibre-optic sensors - Part 1-1: Strain measurement - Strain sensors based on fibre Bragg gratings." IEC 61757-2-2 (2016), "Fibre-optic sensors - Part 2-2: Temperature Measurement - Distributed Sensing." Iten, M. et al., (2015) "Benefits of Global Standards on the Use of Optical Fibre Sensing Systems for the Impact of Construction of New Utilities and Tunnels on Existing Utilities", Proc. Pipelines 2015. Recent Advances in Underground Pipeline Engineering and Construction. 1655 1666, doi: 10.1061/9780784479360.152.

Iten, M. (2011). "Novel Applications of Distributed Fibre optic Sensing in Geotechnical Engineering," PhD Thesis Nr. 19632, ETH Zurich, Switzerland.

Iten, M., Hauswirth, D. and Puzrin, A. (2011). "Distributed Fibre Optic Sensor Develo, Testing, and Eval for

Geotechl Monitoring Applic," Proc. SPIE 7982,Smart Sensor Phenomena, Tech, Networks, Systems.

Jeyapalan, J. K., Bizzarri, R. B., Murray, B., Kottke, P., Morgan, A., Test,E., Harding, A., Sharma, A., Castro, R. and Kantola, J. Q. (2015), “Guidance from Tunnel and Shaft Impact Analyses for DC Clean Rivers Project Design Build Bidding to Protect Critical Pipelines, " ASCE Pipeline Conf. Baltimore, Maryland, August 23-26.

Jeyapalan, J. K., Bizzarri, R. B., Murray, B., Choi, S., Kotter, P. and Test, E. (2014), "Tunnel and Shaft Impact Analyses for DC Clean Rivers Project to Protect Critical Pipelines Carrying Water and Sewage, "North American Society for Trenchless Technology Conf, Orlando, Florida, April 13-17.

Klar, A., Marshall, A. M., Soga, K., and Mair, R. J. (2008)

"Tunneling Effects on Jointed Pipelines, "Canadian

Geotechnical Journal, 45, pp. 131-139.

Mohamad H. (2012). "Temperature and Strain Sensing Techniques Using Brillouin Optical Time Domain Reflectometry," Proc. SPIE 8346, Smart Sensor Phenomena, Technology, Networks, and Systems Integration 012, 83461M; doi:10.1117/12.918329.

Mohamad, H., Soga, K., Bennett, P.J., Mair, R.J. and Lim, C.S. (2012): "Monitoring Twin Tunnel Interactions Using Distributed Optical Fibre Strain Measurements" Journal of Geotechnical and Geoenvironmental Eng, American Society of Civil Engineers, Vol. 138, No. 8, pp. 957-967.

Mohamad, H., Soga, K., and Amatya, B. (2014) “Thermal Strain Sensing of Concrete Piles Using Brillouin Optical Time Domain Reflectometry, " Geotechnical Testing Journal, Vol. 37 (2), 2014, 333-346, [doi:10.1520/GTJ20120176].

Nancey, A., Lacina, B. and Henderson, J. (2007). "Geotextile and Optic Fibres: Feedback After Four Years of Use in Soil". Proc. of the Geosynthetics 2007 Conference, GRI-20 Conference, Washington DC, January 16-17, 2007. SHMII-7, (2015) 7th Intern. Conf. on Structural Health Monitoring of Intelligent Infrastructure, Torino/Italy, July 1-3, Books of Abstract, CD-ROM.

VDI/VDE 2660 (2010), "Experimental stress analysis - 
Optical strain sensor based on fibre Bragg grating Fundamentals, characteristics and sensor testing". VDI Guideline 2660, part 2 (2018), "Technical temperature measurement - Optical temperature sensor based on fibre Bragg gratings - Recommendation on temperature measurement and statement of measurement uncertainty" (green document). December 2018.

Vorster, T. E. B., Klar, A., Soga, K., and Mair, R. J.

(2005)"Estimating the Effects if Tunneling on Existing Pipelines," Journal of Geotechnical and Geoenviron. Eng, ASCE, November, pp. 1399 to 1410 . 